\title{
Incomplete Kawasaki Disease: A Rising Trend
}

\author{
Zainab $\mathbf{M}^{1}$, Guha $\mathbf{S}^{2}$
}

${ }^{1}$ Dr. Madiha Zainab, MBBS, MD Post graduate trainee, ${ }^{2} \mathrm{Dr}$. Suparna Guha MD, Associate Professor, Department of Paediatrics, Vivekananda Institute of Medical Sciences, Kolkata, India.

\section{Address for correspondence:}

Dr. Suparna Guha

E-mail: drs68guha@gmail.com

\section{How to cite}

Zainab M1, Guha S. Incomplete Kawasaki Disease: A Rising Trend. J Nepal Paediatr Soc 2016;36(2):208-212.

doi: http://dx.doi.org/10.3126/jnps.v36i2.15650

This work is licensed under a Creative Commons Attribution 3.0 License.

\section{(c) (i)}

\section{Introduction}

$\mathrm{K}^{\mathrm{a}}$ awasaki disease is the most common cause of acquired heart disease in paediatric population in developed countries and is the $2^{\text {nd }}$ common childhood vasculitis ${ }^{1}$. There is variation in the incidence of paediatric KD between 9.1-32.5/100,000 population in USA $^{2}, 82.8 / 100,000$ in Taiwan, 134.4 in Korea and 265/100,000 in Japan $^{3,4}$. It has a slight male preponderance. The most important risk associated with $\mathrm{KD}$ is coronary artery aneurysm which has an incidence of $20-25 \%$ and a mortality of $1-1.5 \%$. The peak incidence of $\mathrm{KD}$ is from 6 months-2years which includes approximately $50 \%$ of all KD patients ${ }^{6}$. The incidence of KD is around $10 \%$ infants $<6 \mathrm{~m}$ which is similar to $11.2 \%$ in Japan and $7.7 \%$ in Korea ${ }^{7}$. The $1^{\text {st }}$ epidemiologic study on KD from India published in 2011suggested incidence of KD in Chandigarh at least 4.54/100,000 children below $15 y e a r{ }^{8}$.

$\mathrm{KD}$ is a clinical diagnosis. The diagnosis of $\mathrm{KD}$ relies on the early identification of the key clinical components of prolonged fever $>5$ days and any 4 of the 5 criteria given by AHA guidelines(American Heart Association) $)^{9}$. It is further supported by supplementary criteria and echo findings. The uncertainties occur when not all of the classical signs are present and there is incomplete or atypical presentation of 
the disease. Large epidemiologicalstudies estimated around $20 \%$ of all cases fall into incomplete presentation of the group ${ }^{8}$. It has been found that this group is at greatest risk of developing the more serious cardiac sequel of KD i.e. coronary artery aneurysm. This higher risk has been attributed to the delay in diagnosis \& treatment.

The aim of the study was to see the trend of Kawasaki disease in our institute over a period of one year and the objectives were to analyse the clinical profile of KD patients and compare the echo findings of complete and incomplete KD cases and their response to treatment.

\section{Materials and Methods}

This was a retrospective descriptive study done in the paediatric department of VIMS a tertiary care institute in Kolkata from Jan 2015 to Jan 2016. A total of 20 children were diagnosed as KD in the given time frame; of which five were complete $K D$ with typical features(Table 1$)^{9}$. However rest of the 15 cases were not fitting in typical KD. All these 15 cases presented with fever more than five days and rash at some point of illness. Most of them were referred cases. They were being treated with antibiotics. However fever still persisted during their hospital stay eight of them developed oral mucositis, five of them had non purulent conjunctivitis. All infective aetiology was ruled out. These were then suspected for atypical KD, all of them met the supplementary criteria (Fig 1$)^{9}$.

Echo was done which had early changes suggestive of KD in all the atypical cases. They were treated with IVIG and Aspirin and followed up in paediatric rheumatology clinic.

\section{Results}

In our study we had 20 cases diagnosed as KD over a period of one year.

Among the varied clinical manifestations of $K D$ all the children so diagnosed presented with fever and rash mainly diffuse maculopapular (Fig 4).

Supplementary criteria: Raised ESR \& CRP in all cases. Mean ESR was $90.8 \mathrm{~mm}$ in $1^{\text {st }} \mathrm{hr}$ and mean CRP > $24 \mathrm{mg} / \mathrm{dl}$. Anaemia, leucocytosis, thrombocytosispresent in $28 \%$ cases after $1^{\text {st }}$ week (Fig 5).

Echo changes:These were characterised by perivascular cuffing and loss of tapering and or $Z$ score of LAD/RCA> $2.5 \mathrm{SD}$ of $\mathrm{BSA}^{9}$. (Table 6\&7) Of the incomplete $\mathrm{KD}$ all of them had loss of perivascular cuffing which is the earliest sign of coronary artery changes in KD, one had fully developed aneurysm which was diagnosed on the $14^{\text {th }}$ day of illness.

Response to treatment:IVIG was given to all the cases as soon as it was diagnosed. All the cases responded to single dose IVIG $(2 \mathrm{~g} / \mathrm{kg})$ and high dose aspirin (80-100 $\mathrm{mg} / \mathrm{kg}$ ) given till afebrile for 3 days following which the dose was reduced to $5 \mathrm{mg} / \mathrm{kg} / \mathrm{d}$.

Eight weeks follow up with repeat echo was done in all the cases (Fig 8). Five cases had complete resolution of echo changes. All the complete KD cases had no residual echo findings at eight weeks follow up.

Table 1: Diagnosis of Kawasaki disease

\section{$\mathbf{5}$ days of fever AND $\mathbf{4}$ of the $\mathbf{5}$ following criteria}

1. Discrete bulbar conjunctival injection without exudate

2. Erythematous mouth and pharynx, strawberry tongue, and red cracked lips

3. A polymorphous generalised erythematous rash

4. Changes in peripheral extremities consisting of induration of the hands and feet with erythematous palms and soles

5. Cervical lymphadenopathy $(>1.5 \mathrm{~cm})$, ususlly unilateral

Adapted from the American Academy of Pediatrics, Redbook-2000: Report of the Committee on Infectious Disease, $25^{\text {th }}$ ed. (Elk Grove Village, III: American Academy of Pediatrics, 2000), pp. 360-61 


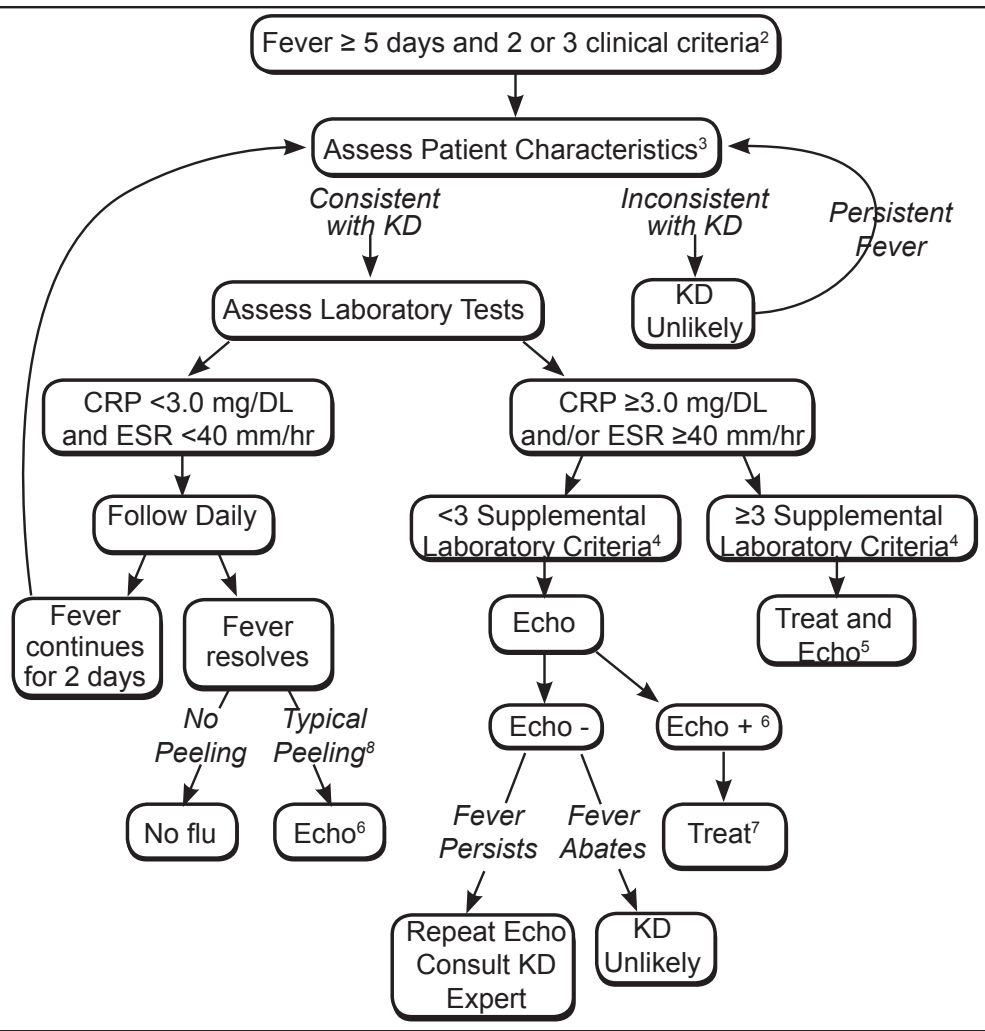

Fig 1: Diagnosis of incomplete KD

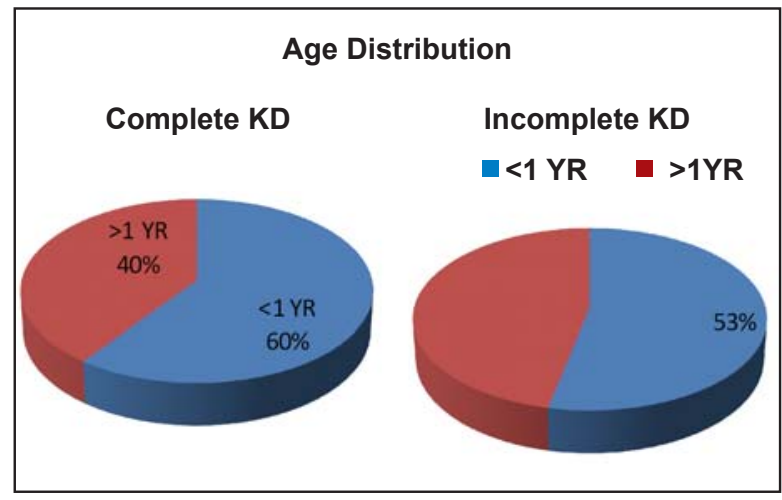

Fig 2: Showing complete and incomplete KD in $<1$ years age

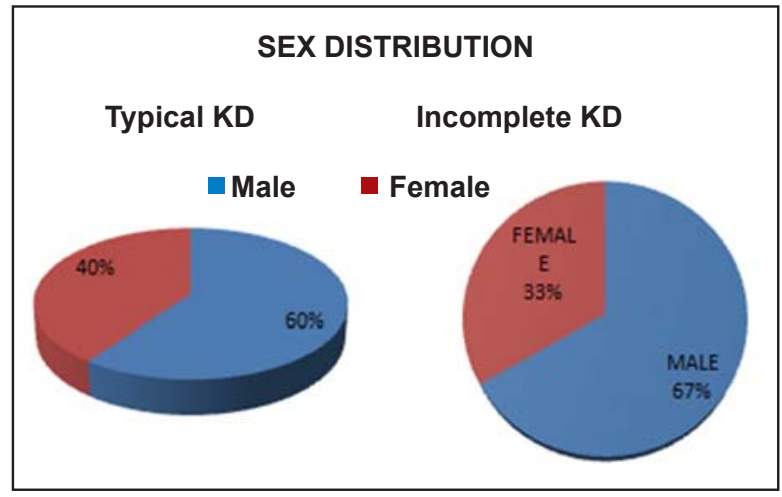

Fig 3: There was male preponderence both in the typical and incomplete KD groups.

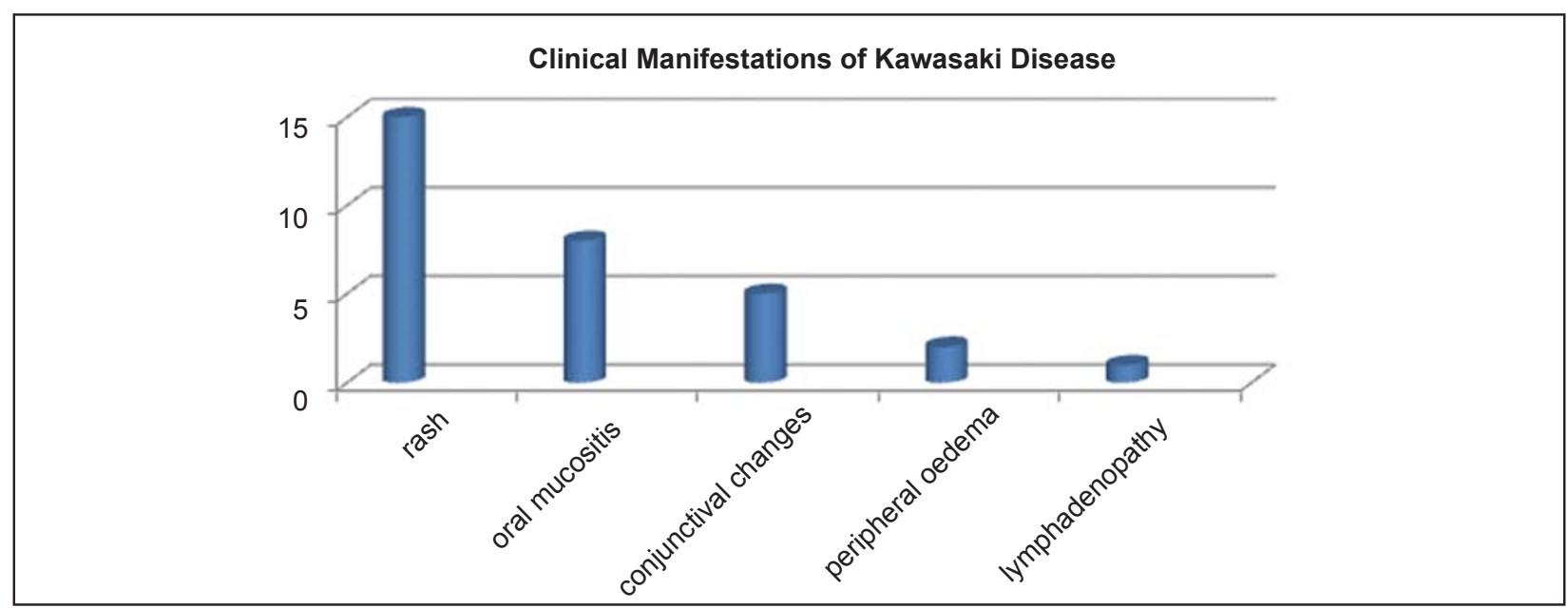

Fig 4: Showing rash as the predominant symptom in the cases followed by oral mucositis, conjunctival changes. Lymphadenopathy was however present in only 1 case. 


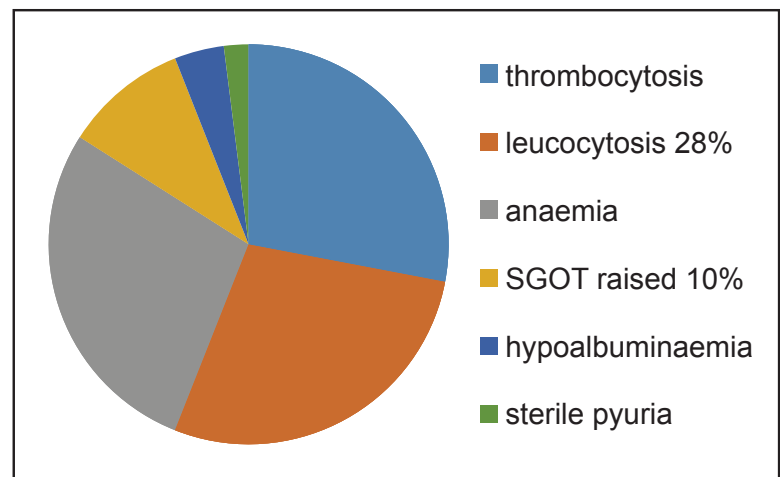

Fig 5: in our study we found that anaemia, leucocytosis and thrombocytosis were present in $28 \%$ of cases. While raised SGOT was present in only $10 \%$ cases.

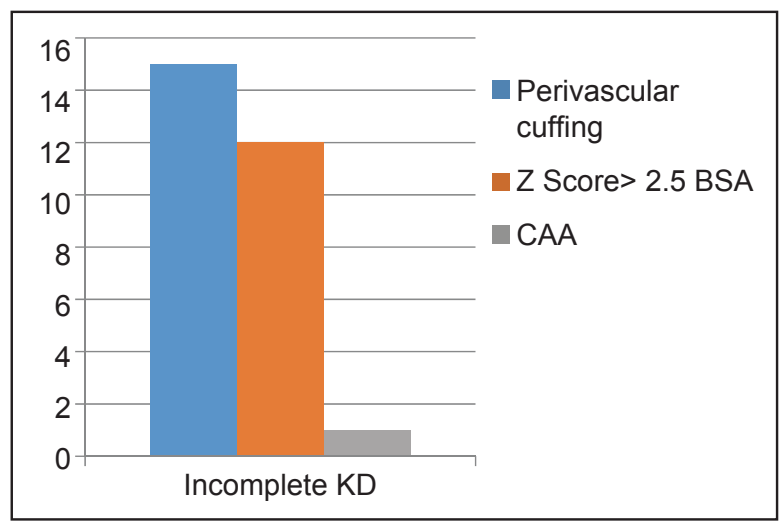

Fig 7: earliest echo changes in KD i.e. perivacular cuffing and loss of tapering were present in all the cases diagnosed as incomplete KD while coronary artery aneurysm developed in one case.

\section{Discussion}

$K D$ is a self limiting vasculitis occurring predominantly in children $<5$ year age.First Indian report was given in 1977 by Tanejaet a/10. 6 cases of Kawasaki disease (KD) diagnosed over a period of one year and review of all the casesreported from India ${ }^{11}$. The diagnosis of KD was based on clinical criteria The mean age of patients was 6.83 years and meanduration of symptoms before diagnosis was 7.5 days.

In a study of patients referred because of possible $\mathrm{KD}$, Burns and colleagues found that standard clinical criteria met in $46 \%$ of cases in whom other diagnoses was established ${ }^{12}$.Youngest patients are more likely to develop atypical features and aneurysm- $60 \%$ developed aneurysm in one series ${ }^{13}$.

$\mathrm{KD}$ is a disease of childhood. About $85 \%$ cases are less than 5 yrs age. In Japan ${ }^{4}$, the highest incidence occurs between 9 and 11 months old in boys, and between three and eight months old in girls. It is increasingly

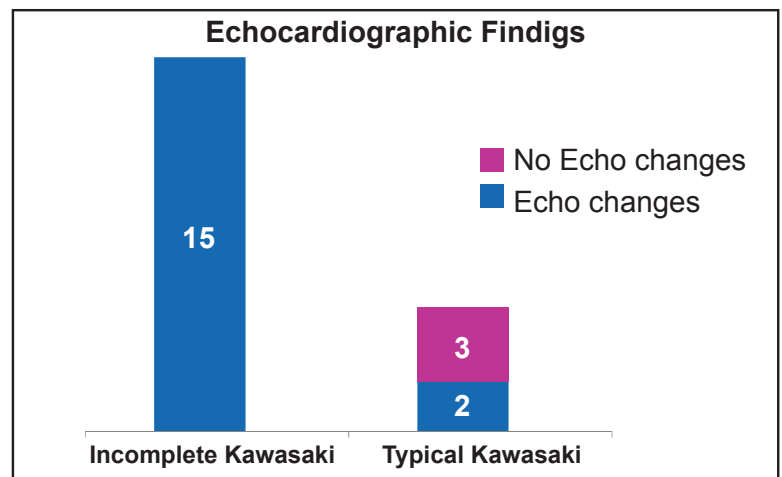

Fig 6: Showing echo changes present in all the incomplete cases while only two of the complete KD cases. Three of the study population did not have echo changes at the time of diagnosis.

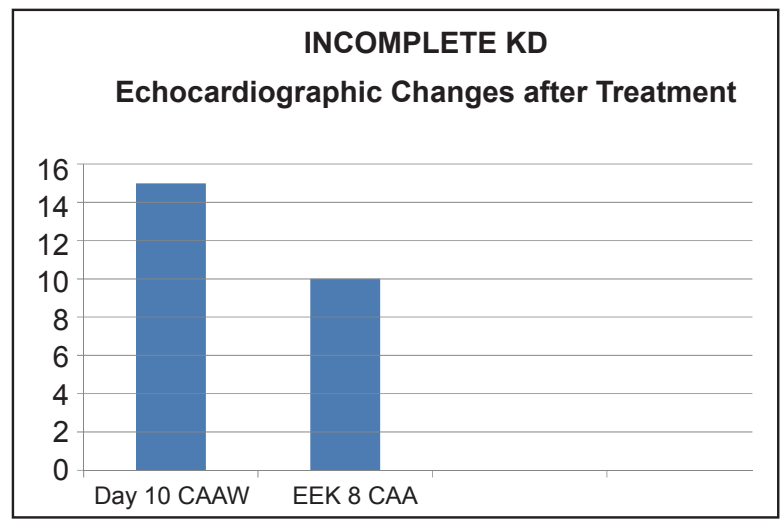

Fig 8: Eight weeks follow up showed resolutionof echo changes in five of the 15 incomplete cases.

reported in infants and more common in males as also evidenced in our study. Baker et $\mathrm{al}^{14}$ studiedthe symptoms in the 10 days prior to diagnosis of KDin 198 patients, and reported that irritability occurredin $50 \%$, vomiting in 44\%, decreased food intake in $37 \%$, diarrhoea in $26 \%$, and abdominal pain in $18 \%$.Cough was reported in $28 \%$, and $19 \%$ had rhinorrhoea. Over the next three to four days,cervical adenitis, conjunctivitis, changes in the buccaland oral mucosa, a pleomorphic rash, and erythemaand edema in the hands and feet develop. In our study fever rash and irritability were present in all the cases. Conjunctival changes and lymphadenopathy occurred later in disease course.

Incomplete KD cases are more common in infants as seen in our study. $75 \%$ of the total cases had incomplete presentation and $60 \%$ of them were < $1 \mathrm{yr}$ age. Unfortunately all had echo changes as early as $10^{\text {th }}$ day of fever and one had aneurysm which was diagnosed on 14 th day of admission. This is in contrast to the study done by Karbuz Aet al in Turkey, which 
showed CAA in $50 \%$ of incomplete $\mathrm{KD}^{16}$. The main reason could be delay in diagnosis in the absence of typical features, delay in referral to our institute thereby delay in treatment. A hospital based study done by Ajanthan $\mathrm{R}$ et al reported total 19 cases in one year of which $74 \%$ were incomplete and $26 \%$ were complete cases ${ }^{17}$.Coronary artery dilation was seen in incomplete criteria group during or after $2^{\text {nd }}$ week due to delay in suspecting KD in the same study reported in Sri Lankan Journal ${ }^{17}$. In our study coronary changes were evident as early as $8^{\text {th }}$ day of illness.

In Chandigarh cohort mortality rate over last 20years is $0.8 \%$ as compared to $0.01-0.08 \%$ in developed countries ${ }^{18}$.Furusho and coworkers ${ }^{19}$ first reported that high-doseIVIG appeared to decrease the incidence of coronaryartery abnormalities. IVIG reduced the incidence of CAA by $78 \%$, and no child sufferedserious adverse effects from the therapy, confirming theremarkable therapeutic potential of IVIG.

\section{References}

1. Kawasaki T. Paediatric acute mucocutaneouslymphnode syndrome clinical observation of 50 cases. Jap J Allergy 1967;16:178222.

2. Maddox RA, Person MK, Joseph LJ. Monitoring the occurrence of Kawasaki Syndrome in US. Proceedings of the Eleventh International Kawaski disease symposium. 2015 abstract 0.03, p28.

3. Uehera R, Belay ED. Epidemiology of KD in Asia, Europe, US. Epidemiology 2012;22:79-85.

4. Singh S, Vignesh P, Burger D. The Epidemiology of KD. A Global Update. Arch Dis Child 2015;100:10845.

5. Singh S, Kawasaki T. Kawasaki disease in Indialessons learnt over 20 yrs. Indian Paediatr 2016 Feb;53(2):119-24.

6. Rowley AH, Shulman ST. Kawasaki syndrome. PaediatrClin North Am 1999;96:313-29.

7. Park YW, Han JW, Hong YM, Ma JS, Cha SH. Epidemiologic study of Kawasaki disease in $6 \mathrm{~m}$ old and young infants. Korean J Paed 2008;51:1320-23.

8. Singh $S$, Aulakh R, Bhalla AK, Suri D, Manojkumar $\mathrm{R}$, Narwa $\mathrm{N}$ et al. Is Kawasaki disease incidence rising in Chandigarh, North India?Arch Dis Child 2011;96:137-48

9. Newburger JW, Takahashi M, Gerber MA. Diagnosis, treatment and long term management of $\mathrm{KD}$. Paediatrics 2004;114:1708-733.

10. Taneja A, Saxena U. Mucocutaneous lymph node syndrome. Indian Paediatr 1977:14:927-31
In our study all patients responded to IVIG and high dose aspirin given till afebrile for 3 days thereafter low dose aspirin started. Follow up echo showed regression of echo changes in all typical KD cases while in eight of the incomplete ones echo changes persisted.

\section{Conclusion}

Kawasaki disease is a medium vessel vasculitis with a high predilection for the coronary arteries. Incomplete $\mathrm{KD}$ is more common in infants and its incidence is on the rise. It is a medical urgency if not diagnosed and treated on time, child may develop coronary artery aneurysm the sequelae of which may be long lasting and devastating. Therefore high index of suspicion is required in any child with prolonged fever, rash and irritability. The diagnosis is mainly clinical and one need not delay administration of IVIG just because an echo has not been performed or echo changes not present at that time.

11. Sridhar MR, Goel H, Anirudh D, Lodha R, Kabra SK. Kawasaki disease: Are we missing the diagnosis? Indian J Pediatr 2005;72(10):873-75.

12. Burns JC, Mason WH,Glode MP, Shulman ST, Melish ME,Meissner C. Clinical and epidemiologic characteristics of patients referred for evaluation of possible Kawasaki disease. United States Multicenter Kawasaki Disease Study Group, JPediatr 1991;118:680-86.

13. S.M. Benseler, B.W. McCrindle, E.D. Silverman. Infections and Kawasaki disease: implications for coronary artery outcome. Arthritis Rheum 2003;48:S513

14. Baker AL, Lu M,Andrew M, Gloria L, Rosalind K. Associated symptoms in ten days before diagnosis of Kawasaki disease. J Pediatr2009;154:592-59.

15. Fukushige J, Takahashi N. Incidence and clinical feature of incomplete Kawasaki disease. ActaPediatr 1994;83:1057-60

16. Karbuz A, Karadeniz C, AldemirKokabas B, Ciffi $\mathrm{O}$, Ozdemir H, Bolkent MG et al. Another face of Kawasaki disease: Turkish J Paediatr 2014;56:392398.

17. Ajanthan R, Witham W. A Study of children with Kawasaki disease. Sri Lanka J Child Health 2003;32:40-43.

18. Singh S, Bhattad S, Gupta A, Suri D, Rawat A, Rohit $\mathrm{M}$ et al. Mortality in children with KD: 20 years experience from tertiary care centre in north India. ClinExpRheumatol 2016;34(3 suppl 97):129-33.

19. Furusho K, Kanuja $\mathrm{T}$. Intravenous gammaglobulin in Kawasaki disease. ActaPaediatrJpn 1991;33(6):799804. 